\title{
Obstacle Avoidance Mobile Robot With Ultrasonic Sensors
}

\author{
Qory Hidayati ${ }^{*}$ \\ ${ }^{1}$ Electrical Enginering Departement State Polytechnic of Balikpapan \\ *qory.hidayati@poltekba.ac.id
}

\begin{abstract}
The robot that can move (mobile robot) is required for observation in difficult circumstances which is difficult to be performed by humans such as extreme temperature, cramped, dark and so on. Robot which is needed, is able to move on its own and can avoid obstacles. Implementation tools through experiments is performed in the laboratory. To determine the direction of the turn is based on the measurement data from the sensor ping ultrasonic range finder, then Arduino will adjust the speed of a DC motor to generate the left and right turn. The test results show mobile robot can move itself and is able to avoid obstacles. When the mobile robot obstacle is stuck in the center with left-right-front, it requires quite a long time to come out.
\end{abstract}

Keywords: mobile robot, arduino, ping sensor

\section{Introduction}

Developments in science and technology are used to meet human needs. Rapid technological development is characterized by many tools that have been created and is operated either manually or automatically, and some people even use the robot as a helper. By using robots, we can do more complicated job and require a high accuracy.

Robot is a mechanical device that can perform physical tasks, both using supervising and human control, or using a program that has been defined before (artificial intelligence). Robots are typically used for heavy duty, dangerous, repetitive and dirty jobs [4].

In its development, robots have been developed to be able to help people in doing complicated, dangerous job and requires high precision and accuracy. For example, is to extinguish the fire in a building which is structurally unstable and many obstacles [1].

This obstacle avoidance robot requires a variety of sensors to perform their functions properly, one of them is a distance measuring sensor robot against the walls of the room. Spacer Sensor uses ultrasonic range finder sensor ping-made Parallax. These sensors will measure the distance of the robot against the wall, and then provide information to the microcontroller on the existence of a wall along the distance of the robot in a room so that the robot can pass or avoid obstacles that are in front, and the side of the robot.

Based on these problems the author took the title "Ruler Distance on Obstacle Avoidance Mobile Robot Using Sensor Ping-Based Arduino", by using the applications of Ping Ultrasonic sensor, the robot is expected can reach a point of interest by avoiding all obstacles both in front and side robot.

\section{Metodology}

The method used in this study a worksteps and a series of activities as follows:

1. Carry out a review of literature material directly related to the proposed research activities

2. Conduct discussions with teammates research to find a solution that is more efficient 
3. Using the method of approach between theory and practices by conducting experiments in laboratory

4. Implement testing is to test the characteristics of the tools made and compared with theories that support this study design

\subsection{System Design}

The Obstacles Avoidance Mobile Robot has hardware as follows: board Arduino Uno rev 3 based microcontroller ATmega328, 1 piece of ultrasonic sensors, 1 piece of servo motors, 1 piece $16 \times 2$ LCD as a viewer sensor readings, 1 pair gearbox with each DC motor, motor driver DCbased IC L293D. The system can be seen in Figure 1 below:

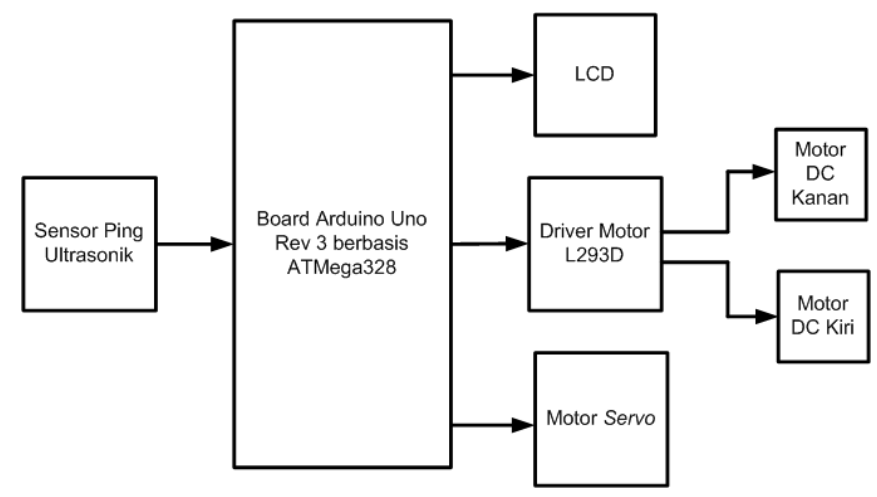

Figure 1: Microcontroller system work design

Whole series of obstacle avoidance robot system can be divided into three main parts: the minimum section ATmega328 microcontroller system using Arduino Uno board rev 3 (includes a power supply section), part of the input, the output section. Sensor input part is used for data retrieval on the environment which will then become the basis of the movement of the robot. The input section consists of 1 ultrasonic sensor. Output section consists of $116 \times 2$ LCD to know the results of sensor readings, 1 servo motor to drive the ultrasonic ping sensor holder, 2 DC motors along with its driver.

\subsection{Mechanical System Design}

This obstacle avoidance robot has a circular shape which has a diameter of 16 $\mathrm{cm}$ with a height of $9 \mathrm{~cm}$ body, but if added to the high altitude of ultrasonic sensors overall robot reaches $12 \mathrm{~cm}$. Body robot uses material $3 \mathrm{~mm}$ thick iron plate. Body robot was made into two levels, namely the base rate for the gearbox and wheels, along with batteries, first-rate equipment and minimum sensors robotic systems. Obstacle avoidance robot body design shown in Figure 2.

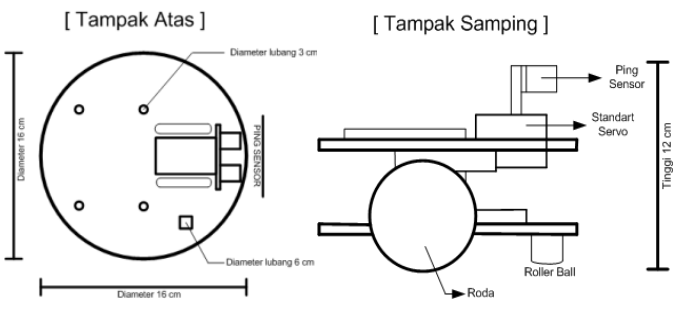

Figure 2 Body robot design

\subsection{Software Design}

Software design is the design process of making program that will be executed by the microcontroller. This program will become a routine that will always be executed when the microcontroller is powered on. The program will be stored in the EEPROM in the microcontroller, so it is only necessary to download the program once to the microcontroller because although the voltage source is switched off, the program is still stored in the EEPROM.

Obstacle avoidance robot program is adjusted to the field conditions that will be used. Here is a program flowchart of the robots: 


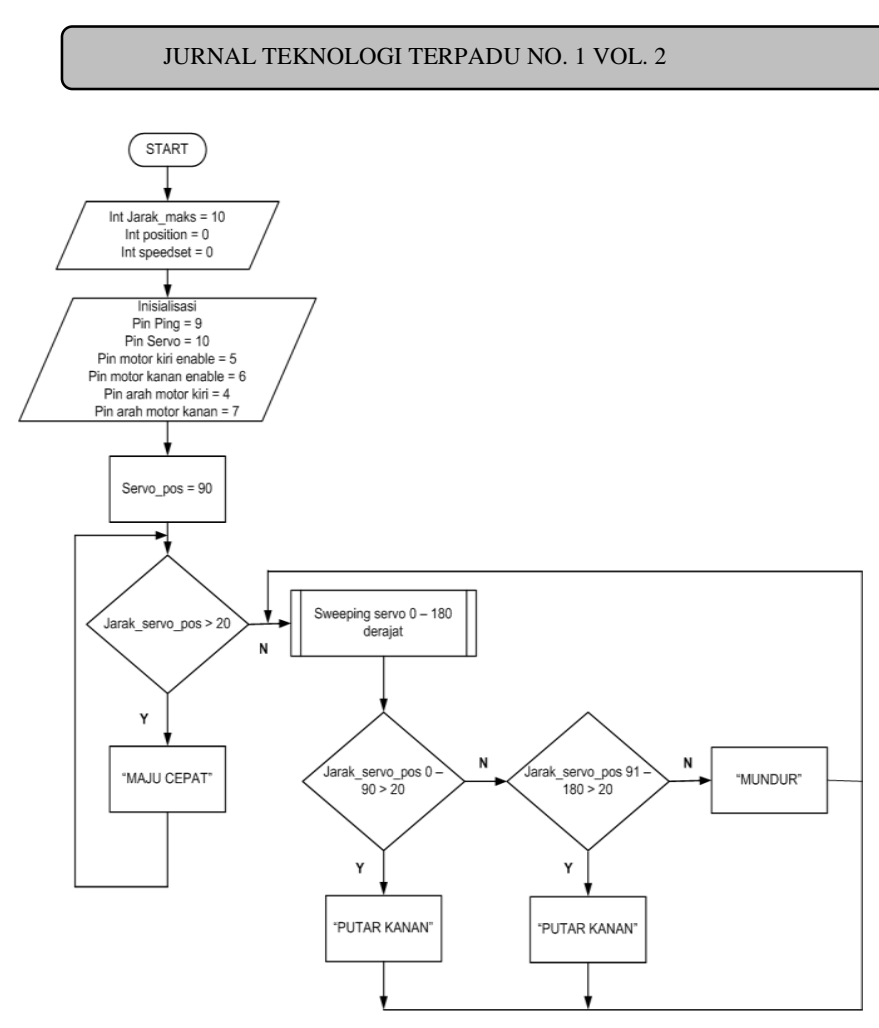

Figure 3 Programming Flowchart

\section{Implementation}

\subsection{The Entire Testing System}

From the test results as table 1 shows, was seen within the test results in a tool was not the same as the calculation using the formula. The differences within the test results to the distance calculation results can be caused by noise. Ping sensor module))) works on the principle of reflection of ultrasonic waves, sometimes the reflection of ultrasonic waves becomes not periodic and lead to inaccurate measurement results. In addition, errors measurement can also occur due to rounding calculations when creating the program.

Table 1 Results of measurements of the average distance and percent errors

\begin{tabular}{|c|c|c|}
\hline $\begin{array}{c}\text { Jarak Aktual Yang } \\
\text { Diinginkan }\end{array}$ & $\begin{array}{c}\text { Jarak Hasil } \\
\text { Pengukuran Rata- } \\
\text { rata }\end{array}$ & Kesalahan (\%) \\
\hline $3 \mathrm{~cm}$ & $3.02 \mathrm{~cm}$ & 0.67 \\
\hline $4 \mathrm{~cm}$ & $4.03 \mathrm{~cm}$ & 0.75 \\
\hline $5 \mathrm{~cm}$ & $5.06 \mathrm{~cm}$ & 1.20 \\
\hline $6 \mathrm{~cm}$ & $6.11 \mathrm{~cm}$ & 1.83 \\
\hline $7 \mathrm{~cm}$ & $7.09 \mathrm{~cm}$ & 1.29 \\
\hline $8 \mathrm{~cm}$ & $8.13 \mathrm{~cm}$ & 1.62 \\
\hline $9 \mathrm{~cm}$ & $9.07 \mathrm{~cm}$ & 0.78 \\
\hline $10 \mathrm{~cm}$ & $10.09 \mathrm{~cm}$ & 0.90 \\
\hline
\end{tabular}

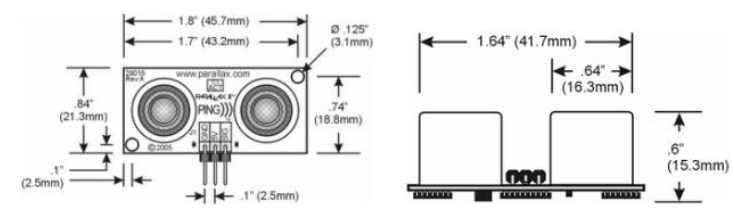

Figure 4 Dimensional ultrasonic sensor

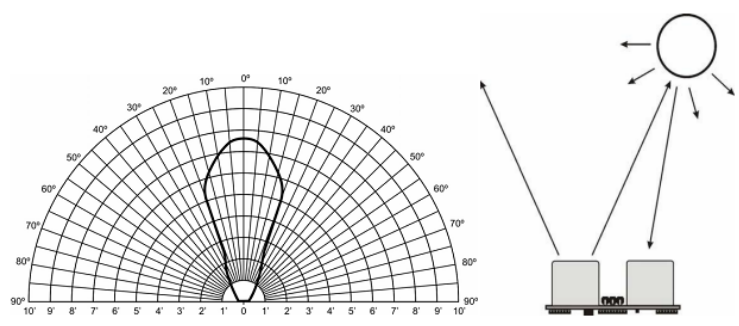

Figure 5 Ping))) test with tube barrier 
On testing the sensor Ping))) in Figure 6 by using a barrier in the form of a cylinder or tube, the maximum measured distance will be shorter than using a barrier board. Testing above shows that the 7.5-inch angle sensor readings are only able to ping at an angle of 0 degrees. While the maximum reading angle is 45 degrees at a distance of 1 inch.

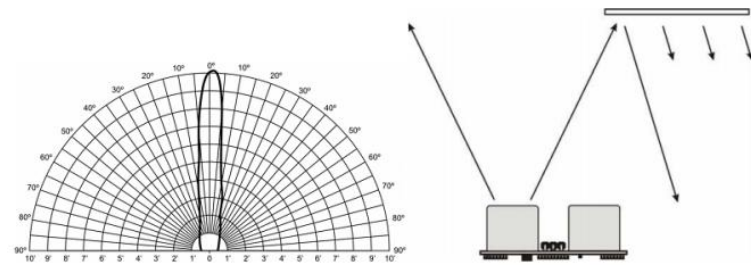

Figure 6 Ping)) test with board barrier (Source: Datasheet PING))) ${ }^{\mathrm{TM}}$ Ultrasonic Distance Sensor, 2006)

The test results in Figure 6 is very different to the test in Figure 5. In this test shows that the distance that can be reached by a ping sensor will be longer compared to using barrier tube, but the angle ping sensor readings will be lower than using a tube.

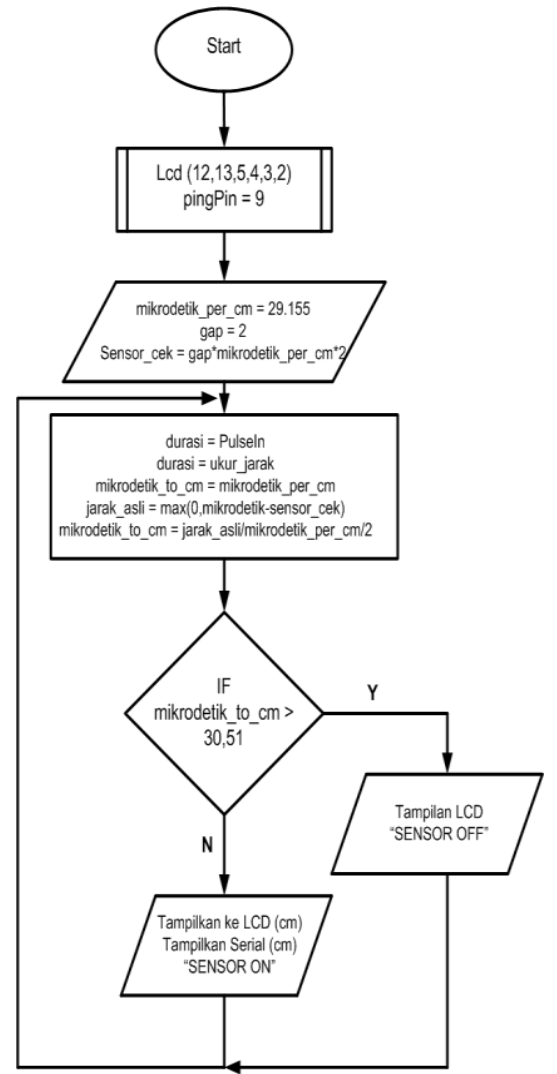

Figure 7 Flowchart distance measurement with sensor PING)))
This test aims to determine the parallax Ping sensor readings can be processed using the Arduino Uno Rev 3 to be output. Testing is performed by connecting the LCD to the pin which is in the Arduino Uno board.

\section{Conclusions}

The conclusion of the preparation of this study are as follows:

1. It has been created robot an obstacle avoidance robot with dimensions of robot body circle diameter of $16 \mathrm{~cm}$ and $12 \mathrm{~cm}$ high. This robot uses ultrasonic sensors as obstacle detection / obstacles and motion system using a DC motor.

2. Sensor Ping))) ultrasonic used for navigation on the robot. These sensors will measure the distance the robot against the wall in the room, the reading sensor Ping))) ultrasonic through SIG port is connected directly to the port on board Arduino, and then displayed via LCD

3. An obstacle avoidance robot using the following left wall method to avoid obstacles with the help of sensors Ping))) ultrasonic, later use as actuators DC motor driver to turn and spin.

\section{Suggestions}

Based on the above conclusions can be given advice regarding the development and improvement of equipment that has been designed in order to obtain maximum results with better accuracy, namely:

1. Level of shortage Parallax Ping sensor can be done via microcontroller programming. Besides the object which is used to reflect, need to be a solid object so the emitted signals can be received back as well.

2. The use of Ping sensor Parallax more on each side of the robot, for example by adding Ping ultrasonic sensors in the left and right of the robot so that the reading distance of obstacle become more efficient and better of course. 


\section{Bibliography}

[1] Budiharto, Widodo., 10 Proyek Robot Spektakuler, Jakarta : Elex Media Komputindo, 2008.

[2] Heryanto, Ary,.Wisnu, Adi., Pemrograman Bahasa C untuk Mikrokontroler Atmega8535, Yogyakarta : Andi Offset, 2008.

[3] Lingga, Wardhana., Mikrokontroler AVR Seri Atmega8535 Simulasi, Hardware, dan aplikasi, Yogyakarta : Andi Offset, 2006.

[4] Pitowarno, Endra., Robotika Desain Kontrol dan Kecerdasan Buatan, Yogyakarta : Andi Offset, 2006.

[5]

\section{Arduino.} Arduino, Datasheet 